\title{
The Metallography of some Ancient Egyptian Implements.*
}

\author{
By Sir Harold Carpenter, F.R.S., and Dr. J. M. Robertson.
}

$\mathrm{I}^{\mathrm{R}}$ RON in ancient Egypt has been the subject of many publications, and, concerning such aspects as the approximate date of the beginning of the Iron Age, the use of meteoritic iron, and the source of the Egyptians' knowledge of iron making, many different opinions have been expressed. With regard to some of these questions the position is such that evidence may be adduced in support of a variety of views each of which is at variance with certain portions of the total available evidence. Concerning the approximate date of the beginning of the Iron Age there are, for example, two main categories of evidence, the direct and the indirect, and generally speaking, the conclusion arrived at depends on which type is regarded as the more reliable. The evidence provided by the discoveries of iron articles, iron-smelting furnaces, or references to iron in writings or paintings constitutes the direct evidence, whereas the existence of hard stone carvings which would appear to have required the use of iron tools in their execution constitutes the indirect evidence.

Only six iron specimens which can be definitely shown to belong to the period 1300 B.c. have been found, whereas iron articles belonging to later periods are fairly plentiful. On the basis of this evidence, Petrie has suggested that iron did not come into general use in Egypt until 1300-1200 B.c., although it was apparently used sporadically for a period of from 2000 to 3000 years before this.

A further indication of the late beginning of the use of iron is provided by the evidence quoted by Rickard, ${ }^{1}$ that mural pictures surviving from the period prior to 2000 B.c. show weapons coloured yellow or red, representing copper or bronze, but none of iron, which was usually coloured blue in paintings subsequent to 1500 B.C. In the long lists of tribute collected in the days of the Eighteenth Dynasty (1580-1350 B.c.) iron is not mentioned, and Rameses II. (1292-1225 B.c.) wrote to the King of the Hittites asking for a dagger. In the innermost sarcophagus of Tut-ankh-amen, who died about 1360 B.c., three iron articles were found-a dagger blade, part of an amuletic bracelet, and a miniature head-rest. Rickard infers from the position of these articles, which lay on the wrappings of the mummy, that they were the most precious things belonging to the dead Pharaoh, and that the iron was more rare and highly prized than the gold of which the sarcophagus was made. Among the funerary chattels found in the annexe of Tut-ankhamen's tomb were some miniature iron implements, and Howard Carter ${ }^{2}$ suggests that these might have been " gifts to the young King to record the arrival or discovery of iron in Egypt."

All the foregoing evidence goes to show that iron, although not unknown in Egypt before 1200 B.c., was very rare, and was probably not manufactured

* Based upon a paper read on May 1 at the annual meeting of the Iron and steel Institute. in that country. The majority of archæologists accept this evidence as conclusive.

If no appreciable quantity of iron existed in Egypt before 1200 B.c., copper and bronze tools must have been the only ones available, and yet from the Fourth Dynasty (2900 B.c.) the Egyptians were accustomed to sculpture hard stones, such as granite and diorite. According to Garland and Bannister, " Many of the antique Egyptian statues are perfect examples of the sculpture's art; the hardest stones were carved and shaped with unfailing accuracy, faultless symmetry and definition : sharp corners with perfect angles and knife-like edges, gracefully curved and plumb straight lines, grooves and serrations: deep and shallow depressions and reliefs, with delicate, undulating contours, or rigidly plane surfaces ".

Sculpture work of this kind is known to have been done for a thousand years before the introduction of bronze, when copper tools only were available-but even with bronze tools it is difficult to understand how this work was accomplished. The hypothesis that the Egyptians possessed some secret method of hardening copper has now been discarded, and two alternative explanations of their method of carving hard stone remain. One, due to Petrie, is that the work was done by means of emery-fed copper or bronze tools ; the other, that steel tools were used. Hadfield " goes so far as to suggest that "the ancient Egyptians were not only able to make steel for tools of all kinds, but also to cement and harden it, or, if not themselves steel-workers, they obtained the necessary material and help from the workmen of another nation".

The existence of the hard stone carvings is difficult to reconcile with the evidence of the specimens found by excavators. The scarcity of iron relics of the period prior to 1200 B.c. may perhaps be explained by corrosion, by the existence of a superstitious objection to the inclusion of iron among funerary objects, or by arguing that the total number of metal specimens found is at best only a small proportion of those that must have been used. These arguments may, however, be met by appealing to the permanency of iron rust, and to the fact that many iron objects belonging to the period subsequent to 1200 B.c. have been found in tombs and elsewhere.

We incline to the view that iron was rare in Egypt until about 1300 B.C., for the evidence of this scarcity implied in the request of Rameses II. to the King of the Hittites, and in the nature and position of the iron objects buried with Tut-ankh-amen, is certainly strong.

The existence of a number of iron specimens definitely known to belong to the period 2900-1450 B.c. shows, however, that the Egyptians were acquainted with this metal for about fifteen hundred years before its use became general. During this, what may be termed, sporadic Iron Age, it was

No. 3162, VoL. 125] 
obtained in limited quantities either by home manufacture or by trade, and it has been argued that an intelligent people like the Egyptians would not have been content with a limited supply of this valuable commodity, but would have applied themselves to extending its production and manufacture. The validity of this argument rests, however, on the assumption that the iron was found to be superior, at any rate in certain respects, to copper and bronze, in the working of which the Egyptians had already acquired remarkable skill. On consideration it is quite clear, however, that the first efforts at ironmaking would be most unlikely to produce a metal which would commend itself to the Egyptians or any other ancient people previously acquainted with the use of bronze.

We are liable to forget that the position of iron in modern civilisation is due to the abundance of its ores, the scale on which it can be manufactured, and the variety of alloys it forms with carbon. None of these considerations would influence its position when it first appeared in Egypt. The spongy mass of iron and slag obtained from the direct furnace required much heating and hammering to get rid of the slag and produce a coherent metallic lump. From this material the desired articles would have to be laboriously cut and forged with frequent reheatings, and the final product-if free from carbon, as most direct iron was-would be softer than bronze, devoid of ornamental attributes, and liable to rust. The manufacture of iron articles was therefore much more troublesome than that of similar articles in bronze, and when finished, the product would not display any properties superior to those of this alloy. It is probable, therefore, that iron when first discovered was developed with most avidity among people not previously acquainted with other metals or not highly skilled in their use. In Egypt conditions were far otherwise, and iron would probably be regarded as a curiosity, or something with possibilities, but not as an alternative to, or an improvement on, existing metals.

The position of iron in ancient Egypt clearly did not depend entirely on acquaintance with the metal, the ores from which it could be extracted, and the means by which this could be accomplished. Numerous other considerations have to be taken into account, and these may be summarised by stating that direct iron when compared with bronze did not possess sufficient advantages to compensate for the greater difficulty experienced in manufacturing useful articles.

The usefulness of iron for tools, weapons, and implements of all kinds would be greatly enhanced when means were discovered for converting it into steel by the introduction of carbon and a further extension of the utility of this metal would follow the discovery of quenching. With the development of these processes of carburising and quenching, iron, because of the increased hardness that could then be conferred on it, would assume a new significance, and it was probably from this time that it began to be taken seriously and the sporadic gave place to the real Iron Age.

Although there is in existence a large collection of ancient specimens of iron, comparatively few of them have been examined by metallurgical methods, and this is largely due to the reluctance of archæologists to submit specimens for examination when they anticipate that this will involve their partial destruction. It is certainly true that examination by chemical methods requires drillings to be taken, but microscopic examination can be carried out simply by polishing a part of the surface, and by this method a considerable amount of information can be obtained from the examination of ancient metal specimens without injuring them.

Through the kindness of Sir Flinders Petrie, we have been able to examine nine representative specimens selected with his assistance from his Egyptian Collection at University College, London. The specimens examined were as follows :-

No. 1. A portion of a sickle. This specimen had been very badly corroded, and consisted mainly of iron oxide held together by a thin sheet of metal. The sickle consisted of two parts, a back and a blade. Sir Flinders Petrie considers that this specimen belonged to the Roman period, and was probably made in the second or third century A.D.

No. 2. A small knife in good condition. It is considered that this belonged to an early. period in the Iron Age, and was probably made about 1200 B.C.

No. 3. A knife with a bronze handle. This specimen was in fairly good condition, although it showed marked surface corrosion and pitting. It is regarded as belonging to the period about 1200 B.c.

No. 4. A small knife in good condition. It is not an Egyptian shape, and is believed to have been imported from Europe about 300 B.C.

No. 5. This specimen is a very primitive piece of work, and it is difficult to say what it is. Sir Flinders Petrie was unable to assign it to any period.

No. 6. A chisel in good condition (Fig. 1). It is supposed to date from about 700 B.c.

No. 7. A hoe in good condition. This specimen is supposed to date from about 800 B.c.

No. 8. An axe head, corroded. It is believed to date from about 900 B.C.

No. 9. An axe head in very good condition (Fig. 2). This specimen is believed to belong to the same period as No. 8, namely, about 900 B.C.

The examination of these specimens was carried out in such a way that practically no damage was done to them. In each specimen a representative

No. 3162, VoL. 125] 
area was polished and examined microscopically, micrographs being taken of typical structures. The hardness of these typical structures was then determined by means of a Brinell hardness tester with a $1 \mathrm{~mm}$. diameter ball. In all the specimens exten-

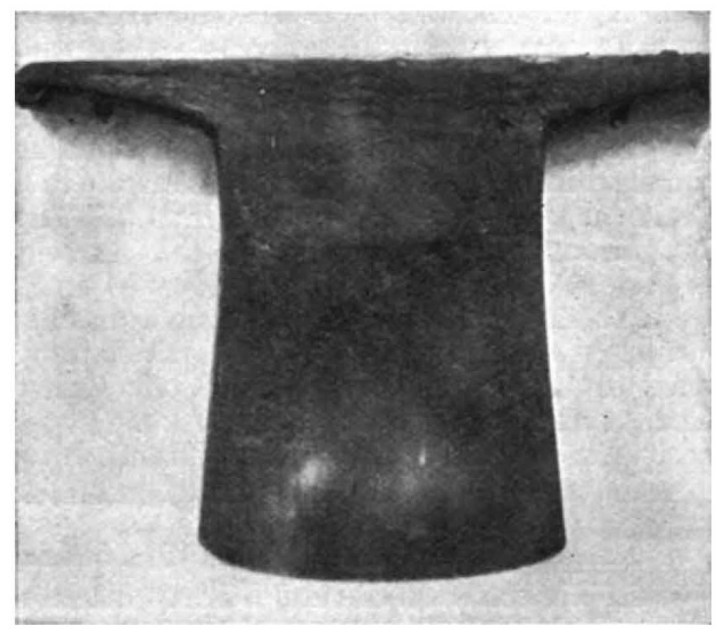

FIG. 2,-Specimen No. 9, an axe head.

sive variations in microstructure were observed. Some of these were clearly the result of carburising and heat treatment, but others were due to variations in the composition of the original metal, which when produced in primitive smelting furnaces consists of particles that have been welded and not melted together.

The principal results that were obtained from examination of the specimens were, briefly, as follow :-

No. 1. This sickle consisted of two portions, a back and a blade. Microscopic examination showed that the back consisted mainly of ferrite with a little carbide, indicating that it had been made from iron containing a very small proportion of carbon. The blade, however, had been carburised so as to bring the carbon content up to about 0.35 per cent. It had then been quenched in water and tempered at about $600^{\circ} \mathrm{C}$. (Fig. 3).

No. 2. This specimen, presumably made in the first place from almost pure iron, had been carburised so that the carbon content was raised to about 0.7 per cent at the edge. From the edge towards the back the carbon content decreased progressively, and the microstructure and hardness varied accordingly. After carburising, this knife had been heated to about $750^{\circ} \mathrm{C}$. and air cooled-thus producing a hardness of 269 Brinell at the edge.

No. 3. This specimen had been given a similar treatment to No. 2, and the variations in microstructure were almost identical.

No. 4. This specimen had not been carburised or subjected to any other special heat treatment. It was a double-edged knife or dagger, and, whereas the middle of the blade was small grained and contained a fair amount of carbon, the edges were large grained and consisted of soft ferrite. The hardness of the middle of the knife varied between 137 and 143 Brinell; that of the edges varied between 95 and 107 Brinell.

No. 5. This specimen contained a small amount of carbon and had been water quenched, thus producing a hardness which varied between 160 and 197 Brinell.

No. 6. This chisel had been carburised so as to produce a carbon gradient which varied from about 0.6 to 0.8 per cent at the edge to about 0.15 per cent $1 \frac{1}{2}$ in. from the edge. It had then been heated at the edge and quenched by immersing the edge only.

No. 7. This hoe had been forged from direct iron and had received no further treatment.

No. 8. This axe head was badly corroded. It had been carburised, but the treatment had not produced the highest carbon content at the edge. It had then been quenched, but the original hard edge had evidently been removed by sharpening. The highest hardness number obtained was 229 Brinell in an area of high carbon at some distance from the edge ; the hardness at the edge was 207 Brinell.

No. 9. This axe head appeared never to have been used and was still protected by a blue film of oxide formed during the last heat treatment. For this reason it had not been corroded and the edge was sharp and regular. The carburising treatment had produced a carbon content of about 0.9 per cent at the edge, decreasing to a very small amount at 1 in. from the edge. Quenching the edge had resulted in the production of a hardness of 444 Brinell at the edge, and a progressive decrease in hardness to 62 Brinell at $1 \mathrm{in}$. from the edge.

It is evident from the examination of these nine

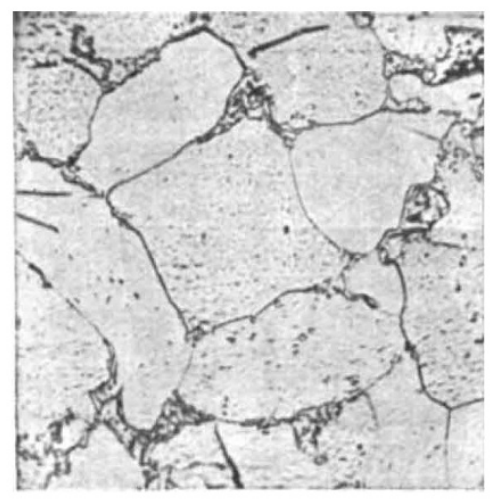

Fra. 3.-Specimen No. 1 ; $(a)$ back; $(b)$ blade. $\times 820$

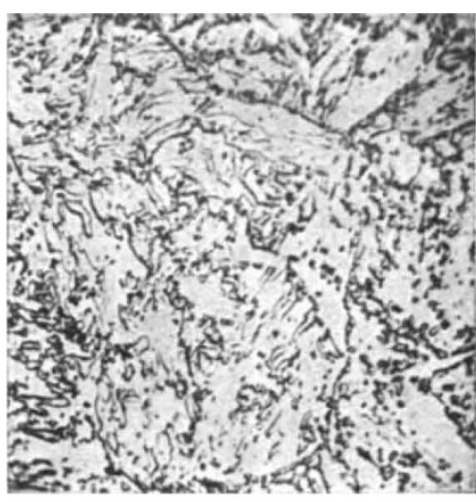

specimens that although the Egyptian process of extracting iron from its ores was very primitive and resulted in the production of almost pure iron containing some slag, yet the metal workers of the period were able to produce in small articles a great variety of properties by means of carburising and heat treatment. All the articles examined do not show the same degree of skill in their manufacture

No. 3162 , VoL. 125] 
and heat treatment, even when they are considered according to their age. But even at the present time there are notable differences in the extent to which the metallurgical knowledge and skill of the community is exhibited by different products, and the same would certainly hold in ancient Egypt when the facilities for the spread of knowledge were, by comparison, very meagre.

So far as we know, the facts disclosed by the present work constitute the first definite evidence that carburising, quenching, and the advantages of heat treatment generally, were known and understood many centuries before the Christian era. Hitherto, the earliest direct evidence of hardening has been that provided by Hanemann, ${ }^{5}$ who observed a hardened structure at the edge of a specimen found during the excavations on the site of Steinsburg at Romhild in Thuringen. This specimen belonged to a period about the beginning of the Christian era. Indirect evidence of quenching at a much earlier date is provided by a reference in Homer.

As already stated, the introduction of carburising and quenching would entirely alter the position of iron in comparison with bronze, and in our opinion it is probable that the Iron Age in Egypt did not properly begin until these processes were under- stood. In other words, it was not until iron had been converted into steel that the Egyptians obtained a range of alloys which were superior in properties to bronze and capable of more varied applications. In countries, however, where bronze was practically unknown, where notable skill in its manipulation had not been attained, or where the requisite ores were not readily available, the extensive manufacture of iron would follow more closely on its first discovery.

There is no reason to suppose that the specimens examined in the present work represent the earliest specimens to be carburised and quenched. The investigation has shown, however, that these processes were in use in the period 1200-800 B.c. As it was about this time that iron came into common use in Egypt, the information now obtained provides a substantial argument in support of the view that the discovery of carburising and quenching was the cause of the extensive utilisation of iron.

$\therefore$ T. A. Rickard : Journal of Iron and Steel Institute, No. II., p. 323 ; 1929

Howard Carter: Illustrated London News, July 2, 1928

3 H. Garland and C. O. Bannister: "Ancient Egypt Metallurgy" (London, 1927).

4 Sir Robert Hadfield : Journal of the Iron and Steel Institute, No. I. p. $134 ; 1912$.

s H.' Hanemann: International Journal of Metallography, vol. 4 p. $248 ; 1913$.

\section{Chinese and Malayan Medicine.}

$I^{\mathrm{N}}$ $\mathrm{N}$ his presidential address to the Chemical Section of the British Association last year, Prof. G. Barger pointed out that "the use of vegetable drugs led pharmacis s to examine the constituents of plants and thus the foundations of descriptive biochemistry were laid ". He suggested later on that "whilst organic chemists are often eager to investigate the constitution of animal and vegetable substances, they are less ready to undertake the preliminaries of purification and isolation and are therefore less apt to discover new ones".

So far as Germany and Great Britain are concerned, it is probably true that less work is being done on the isolation of the proximate constituents of plants and that in France the additions to such knowledge are of a strictly limited character. On the other hand, there is a distinct growth of such work in India, China, and Japan, and there are signs of a revival of interest in it in the United States. The earlier British and German investigations of this kind were usually devoted to severely practical ends, such as the isolation of active principles from vegetable drugs or the preparation of colouring-matters from natural dyestuffs, and it is just possible that the decline of interest is largely due to failure in supplies of new raw material worth examination. Directors of laboratories associated with the application of chemistry to medicine are apt to be afflicted by enthusiastic and credulous collectors of native drugs, who bring home an ounce or two of mouldy roots and a romantic story of marvellous cures of diabetes, tuberculosis, or cancer, and expect the chemist to examine the one and believe the other.

Much valuable work has been wasted in examining material of this kind. Though there is still much to be done, we already have much information linking up the groups of the systematic botanist with particular types of chemical compounds, and there are already clear indications that in the future, work on the constituents of plants is likely to proceed on systematic lines to be settled by cooperation between the botanist and the chemist. In this connexion it is satisfactory to find Dr. Hooper employing his well-earned leisure in identifying and recording the botanical sources of the drugs to be found in Chinese pharmacies in Malaya. ${ }^{1}$ The particular specimens identified were collected by Mr. I. H. Burkill when Director of Gardens, Straits Settlements. The number of specimens dealt with is 456 , and they are mostly of plant origin. The Chinese name of each drug is given, followed by the Romanised Mandarin transliteration. The botanical source is then stated, whereever possible, and a note as to the composition, uses, etc., of the drug is added.

Some of these substances were once familiar drugs in Europe, but have long been obsolete. Many of them are still in common use in European medicine; for example, Datura Metel, the usual source of the valuable alkaloid hyoscine; Hydnocarpus anthelmintica, the seed oil of which is one of the raw materials used in preparing the derivatives of chaulmoogric and hydnocarpic acids used in the modern treatment of leprosy ; rhubarb root, for supplies of which European druggists are still dependent upon Chinese collectors; and a considerable number of aromatic drugs and spices such as mint, anise, dill and ginger.

The most interesting materials, however, are those which have not acquired fame in Europe, of which Achyranthes bidentata Blume is an example.

$$
\text { No. 3162, VoL. 125] }
$$

